\title{
Case-control study of presenilin-1 intronic polymorphism in sporadic early and late onset Alzheimer's disease
} Minoru Yasuda, Nobutsugu Hirono, Kiyoshi Maeda, Toru Imamura, Etsuro Mori,
Chikako Tanaka
Hyogo Institute for Aging Brain and Cognitive Disorders, Himeji, Japan

M Yasuda

N Hirono

K Maeda

T Imamura

E Mori

C Tanaka

Correspondence to: Dr Minoru Yasuda, Hyogo Institute for Aging Brain and Cognitive Disorders, 520 Saisho-ko, Himeji 670-0981, Japan. Telephone 0081792 95 5511; fax 008179295

8199; email

yasuda@hiabcd.go.jp

Received 23 January 1998 and in revised form 20 October 1998

Accepted 3 November 1998

\begin{abstract}
Objective-Presenilin-1 is a major causative gene for early onset familial Alzheimer's disease, and the apolipoprotein $\mathrm{E} \& 4$ allele is a major genetic risk factor known to influence late onset and sporadic early onset Alzheimer's disease. The presenilin-1 1/1 genotype has recently been reported to be associated with sporadic Alzheimer's disease. The purpose of this study is to determine whether Alzheimer's disease is associated with presenilin-1 gene polymorphism and the apolipoprotein $\mathrm{E}$ genotype in an extended case-control study.

Methods-An examination was conducted on 217 patients with Alzheimer's disease, along with an equal number of age and sex matched controls derived from the same community in a Japanese population, by using a $\chi^{2}$ test for homogeneity and a logistic regression analysis. A metaanalysis of data from the literature on allele frequencies in Alzheimer's disease and control populations was used for comparison with the Japanese allele frequencies obtained in this study.

Results-The presenilin-1 allele-1 frequencies were similar in patients with early onset Alzheimer's disease (0.61) and younger controls $(0.61)$, and in those with late onset Alzheimer's disease (0.63) and elderly controls $(0.63)$. We found no evidence for a possible association between the presenilin-1 polymorphism and the apolipoprotein $\mathrm{E} \& 4$ allele. However, the meta-analysis showed that the association between the presenilin-1 1/1 genotype and Alzheimer's disease was significant (Peto odds ratio $=1.16, \quad 95 \%$ confidence interval=1.04-1.31).

Conclusions-These results suggest a subtle but positive association of presenilin-1 gene polymorphism with Alzheimer's disease, although Japanese data in this study which failed to support such a relation would indicate an ethnic variation.

(F Neurol Neurosurg Psychiatry 1999;66:722-726)
\end{abstract}

Keywords: Alzheimer's disease; presenilin-1; metaanalysis

Alzheimer's disease is a neurodegenerative disorder and is the most common cause of dementia in elderly people. ${ }^{1}$ Although the age of onset is variable, most cases of Alzheimer's disease occur at a late age (late onset Alzheimer's disease). An association between Alzheimer's disease and the apolipoprotein E (apoE) 84 allele has been reported in both familial $^{2}$ and sporadic late onset Alzheimer's disease. ${ }^{3}$ The apoE $\varepsilon 4$ allele increases the risk and lowers the age of onset distribution in a dose dependent fashion. ${ }^{4}$ However, only half of all patients with Alzheimer's disease have the apoE $\varepsilon 4$ allele, and a substantial number of people having apoE $\varepsilon 4$ alleles do not develop Alzheimer's disease. These facts indicate that another gene in combination with the apoE $\varepsilon 4$ allele may be involved in sporadic Alzheimer's disease.

In a linkage study of pedigrees having early onset Alzheimer's disease in which the disease has been shown to segregate as an autosomal dominant trait, presenilin-1 (PS1) has been identified on chromosome 14 through positional cloning. ${ }^{5}$ Most early onset familial Alzheimer's disease pedigrees from various ethnic backgrounds are linked to mutations in PS1, many of which are missense mutations. ${ }^{6}$ Mutations in genes coding for PS1 may affect the metabolism of amyloid precursor protein, resulting in an increase in the production of amyloid $\beta 1-42 .^{78}$ These findings suggest that PS1 might have relevance in general Alzheimer's disease pathogenesis.

An important association was reported between a PS1 intronic polymorphism situated 3' of exon 9 of the PS1 gene and late onset, sporadic Alzheimer's disease. ${ }^{9}$ The polymorphism is the result of an $\mathrm{A} / \mathrm{T}$ to $\mathrm{C} / \mathrm{G}$ substitution, in which the first, the more common allele, is designated allele- 1 , and the second is designated allele-2. This study also reported that the PS1 allele-1 was overrepresented in white Americans with late onset Alzheimer's disease, but was not seen in AfroAmericans. However, other studies have shown conflicting results. ${ }^{10-24}$ These prompted us to examine the association between the PS1 allele-1 and Alzheimer's disease in an extended casecontrol study in a Japanese population. We also evaluated the apoE genotype and examined the interaction between PS1 polymorphism and the apoE $\varepsilon 4$ allele.

\section{Methods}

SUBJECTS

Patients with Alzheimer's disease were recruited from those who were consecutively admitted to Hyogo Institute for Aging Brain and Cognitive Disorders (HI-ABCD) for 
examination between October 1994 and December 1996. All patients were examined by both neurologists and psychiatrists during an admission of more than 1 month and were given routine laboratory tests, standard neuropsychological examinations, EEC, MRI of the brain, MR angiography of the neck and head, and cerebral perfusion/metabolism studies by PET or single photon emission computed tomography (SPECT). ${ }^{25}$

The control group was comprised of subjects from three sources: 768 subjects (age range 21-90 years) in the HI-ABCD established population for sex difference study, who were genotyped for apoE as previously described. ${ }^{26}$ Seventy two subjects (age range 23-80 years) were volunteers enrolled at the HI-ABCD for PET study from the community. ${ }^{25}$ Finally, 37 elderly subjects ranging in age from 70 to 93 years were recruited from an old people's home. These subjects had complete neurological and medical examinations that showed that they were free of significant illness and had mini mental state examination ${ }^{27}$ scores $>28$. For each patient, a control subject was drawn randomly from the combined control population, and matched for sex and age (within 2 years) at the time of diagnosis. All case-control pairs were selected on the basis of (1) the patient having a diagnosis of probable Alzheimer's disease according to the criteria of the National Institute of Neurological Disease and Stroke/ Alzheimer's Disease and Related Disorders

Table 1 Distribution of the intronic polymorphism in the presenilin-1 gene

\begin{tabular}{|c|c|c|c|c|c|}
\hline & \multicolumn{3}{|l|}{ Genotype } & \multicolumn{2}{|c|}{ Allelet } \\
\hline & $1 / 1$ & $1 / 2$ & $2 / 2$ & 1 & 2 \\
\hline Younger control & $21(0.36)$ & $30(0.51)$ & $8(0.14)$ & 0.61 & 0.39 \\
\hline ApoE $\varepsilon 4$ non-carriers & $14(0.33)$ & $22(0.51)$ & $7(0.16)$ & 0.58 & 0.42 \\
\hline ApoE $\varepsilon 4$ carriers & $7(0.44)$ & $8(0.50)$ & $1(0.06)$ & 0.68 & 0.32 \\
\hline Early-onset AD & $21(0.36)$ & $30(0.51)$ & $8(0.14)$ & 0.61 & 0.39 \\
\hline ApoE $\varepsilon 4$ non-carriers & $9(0.36)$ & $13(0.52)$ & $3(0.12)$ & 0.62 & 0.38 \\
\hline ApoE $\varepsilon 4$ carriers & $12(0.35)$ & $17(0.50)$ & $5(0.15)$ & 0.62 & 0.38 \\
\hline Elderly control & $59(0.37)$ & $80(0.51)$ & $19(0.12)$ & 0.63 & 0.37 \\
\hline ApoE $\varepsilon 4$ non-carriers & $50(0.39)$ & $61(0.48)$ & $17(0.13)$ & 0.63 & 0.37 \\
\hline ApoE $\varepsilon 4$ carriers & $9(0.30)$ & $19(0.63)$ & $2(0.07)$ & 0.62 & 0.38 \\
\hline Late-onset $\mathrm{AD}$ & $61(0.39)$ & $76(0.48)$ & $21(0.13)$ & 0.63 & 0.37 \\
\hline ApoE $\varepsilon 4$ non-carriers & $26(0.38)$ & $34(0.49)$ & $9(0.13)$ & 0.62 & 0.38 \\
\hline ApoE $\varepsilon 4$ carriers & $35(0.39)$ & $42(0.47)$ & $12(0.13)$ & 0.63 & 0.38 \\
\hline
\end{tabular}

${ }^{\star}$ Number of subjects (frequency).

†Frequency. $\mathrm{AD}=$ Alzheimer's disease.

Table 2 Apolipoprotein $E$ allele frequencies among presenilin-1 genotypes

\begin{tabular}{|c|c|c|c|c|c|}
\hline & \multicolumn{3}{|c|}{ Presenilin-1 genotype } & \multicolumn{2}{|c|}{ Allelet } \\
\hline & $1 / 1$ & $1 / 2$ & $2 / 2$ & 1 & 2 \\
\hline \multicolumn{6}{|c|}{ Younger control: } \\
\hline$\varepsilon 2$ & $2(0.05)$ & $3(0.05)$ & $1(0.06)$ & 0.58 & 0.42 \\
\hline$\varepsilon 3$ & $33(0.79)$ & $48(0.80)$ & $14(0.88)$ & 0.60 & 0.40 \\
\hline$\varepsilon 4$ & $7(0.17)$ & $9(0.15)$ & $1(0.06)$ & 0.68 & 0.32 \\
\hline \multicolumn{6}{|c|}{ Early onset $\mathrm{AD}$ : } \\
\hline$\varepsilon 2$ & $4(0.10)$ & $2(0.03)$ & $1(0.06)$ & 0.61 & 0.39 \\
\hline$\varepsilon 3$ & $25(0.60)$ & $34(0.57)$ & $10(0.63)$ & 0.60 & 0.40 \\
\hline$\varepsilon 4$ & $13(0.31)$ & $24(0.40)$ & $5(0.31)$ & 0.61 & 0.39 \\
\hline \multicolumn{6}{|c|}{ Elderly control: } \\
\hline$\varepsilon 2$ & $8(0.07)$ & $5(0.03)$ & $3(0.08)$ & 0.66 & 0.34 \\
\hline$\varepsilon 3$ & $101(0.86)$ & $135(0.84)$ & $33(0.87)$ & 0.63 & 0.37 \\
\hline$\varepsilon 4$ & $9(0.08)$ & $20(0.13)$ & $2(0.05)$ & 0.61 & 0.39 \\
\hline \multicolumn{6}{|c|}{ Late onset $\mathrm{AD}$ : } \\
\hline$\varepsilon 2$ & $2(0.02)$ & $2(0.01)$ & $1(0.02)$ & 0.60 & 0.40 \\
\hline 83 & $81(0.66)$ & $103(0.68)$ & $26(062)$ & 0.63 & 0.37 \\
\hline$\varepsilon 4$ & $39(0.32)$ & $47(0.31)$ & $15(0.36)$ & 0.62 & 0.38 \\
\hline
\end{tabular}

$\star$ Number of alleles (frequency)

†Frequency. $\mathrm{AD}=$ Alzheimer's disease.
Association (NINCDS/ADRDA), ${ }^{28}$ (2) a negative family history for dementia in both first and second degree relatives on an informant based assessment, and (3) the availability of a blood sample for the patients, and for the matched controls.

Before beginning this study, informed consent was obtained for all patients and from all volunteers according to the Declaration of Human Rights, Helsinki, 1975. All procedures were strictly followed according to the clinical study guidelines of the ethics committee, Hyogo Institute for Aging Brain and Cognitive Disorders (HI-ABCD), 1993, and was approved by the internal review board.

\section{DNA ANALYSIS}

Peripheral leucocytes were separated by Monopoly resolving medium (ICN Biomedicals Inc, CA, USA) according to the manufacturer's protocol. The separated leucocytes were washed once with phosphate buffered saline. Genomic DNA was then extracted with a Genomix DNA extraction kit (Talent Corp, Trieste, Italy) according to the manufacturer's protocol. PS1 genotyping was performed according to the protocol of Wragg et al, ${ }^{9}$ and apoE genotyping was performed according to the method of Wenham et al. ${ }^{29}$

\section{STATISTICAL ANALYSIS}

Analyses were conducted using SAS Release 6.10 software (SAS Institute Inc). We stratified the patient groups by age of onset (early onset< 65 years, late onset $\geqslant 65$ years) to see if age of onset was confounding a potential genetic association. We also stratified the data on the basis of the presence or absence of copies of the apoE $\varepsilon 4$ allele. As an association with the $1 / 1$ genotype and late onset Alzheimer's disease has been proposed, ${ }^{9}$ we examined differences in the $1 / 1$ genotype frequency between patients and controls combining the $1 / 2$ and $2 / 2$ groups as the reference by using the $\chi^{2}$ test for homogeneity. To examine whether the PS1 genotype predicts Alzheimer's disease, we used a multiple logistic regression analysis, with diagnosis (AD $v$ control) as a dependent variable and the PS1 and apoE genotypes as independent variables.

\section{META-ANALYSIS}

For the meta-analysis of the frequency of the PS1 1/1 genotype in controls and patients with Alzheimer's disease, we searched Medline for the period 1995 to 1998 for all entries containing both "presenilin" and "Alzheimer's disease". The retrieved articles or letters, excluding abstracts, were identified. We included only studies in which: (1) data presentation was in such a manner that PS1 allele frequencies could be calculated, and (2) the ethnic background of each patient was identified. The meta-analysis was performed using the method of Peto's fixed effect model. ${ }^{30}$

\section{Results}

From the Alzheimer's disease and control subject pools, a sample of 217 clinically probable patients with Alzheimer's disease and their age 
Table 3 Interaction between apolipoprotein $E \& 4$ allele frequency and presenilin-1 allele-1 frequency by logistic regression analysis

\begin{tabular}{llrl}
\hline Variable & $\begin{array}{l}\text { Odds ratio } \\
(95 \% \text { CI })\end{array}$ & Wald $\chi^{2}$ & Probability \\
\hline Early onset $v$ younger control: & & & \\
ApoE $\varepsilon 4$ frequency & $3.2(2.6-3.9)$ & 11.925 & 0.001 \\
PS1 allele-1 frequency & $1.0(0.4-1.5)$ & 0.011 & 0.917 \\
Late onset $v$ elderly control: & & & \\
ApoE $\varepsilon 4$ frequency & $4.9(4.4-5.4)$ & 42.261 & 0.000 \\
PS1 allele-1 frequency & $1.0(0.7-1.4)$ & 0.009 & 0.925 \\
\hline
\end{tabular}

$\mathrm{PS} 1=$ presenilin $-1 ; \mathrm{AD}=$ Alzheimer's disease

and sex matched controls were utilised for the present analysis. From each group of 217, there were 158 women and 59 men. Of 217 probable patients with Alzheimer's disease, 59 (31 women, 28 men, mean (SD) age at diagnosis $=62.1(4.9)$ years were early onset (mean age of onset $=58.6$ (4.9) years), and 158 (107 women, 51 men, mean age at diagnosis $=75.7$ (6.0 years) were late onset (mean age of onset $=73.0$ ( 5.9 ) years). The mean ages of age and sex matched controls for early and late onset Alzheimer's disease were 61.8 (4.8) and 75.7 (6.3) years, respectively. The apoE allele distribution of patients with Alzheimer's disease $(\varepsilon 2 / 3,4 \% ; \varepsilon 2 / 4,1 \% ; \varepsilon 3 / 3,39 \% ; \varepsilon 3 / 4$, $46 \% ; \varepsilon 4 / 4,9 \%$ ) was significantly different from that of controls $(\varepsilon 2 / 310 \%, \varepsilon 2 / 40 \%, \varepsilon 3 / 369 \%$,

PS1 1/1 genotype frequency

Reference ( $n: A D /$ control) $(\mathrm{AD} /$ control)

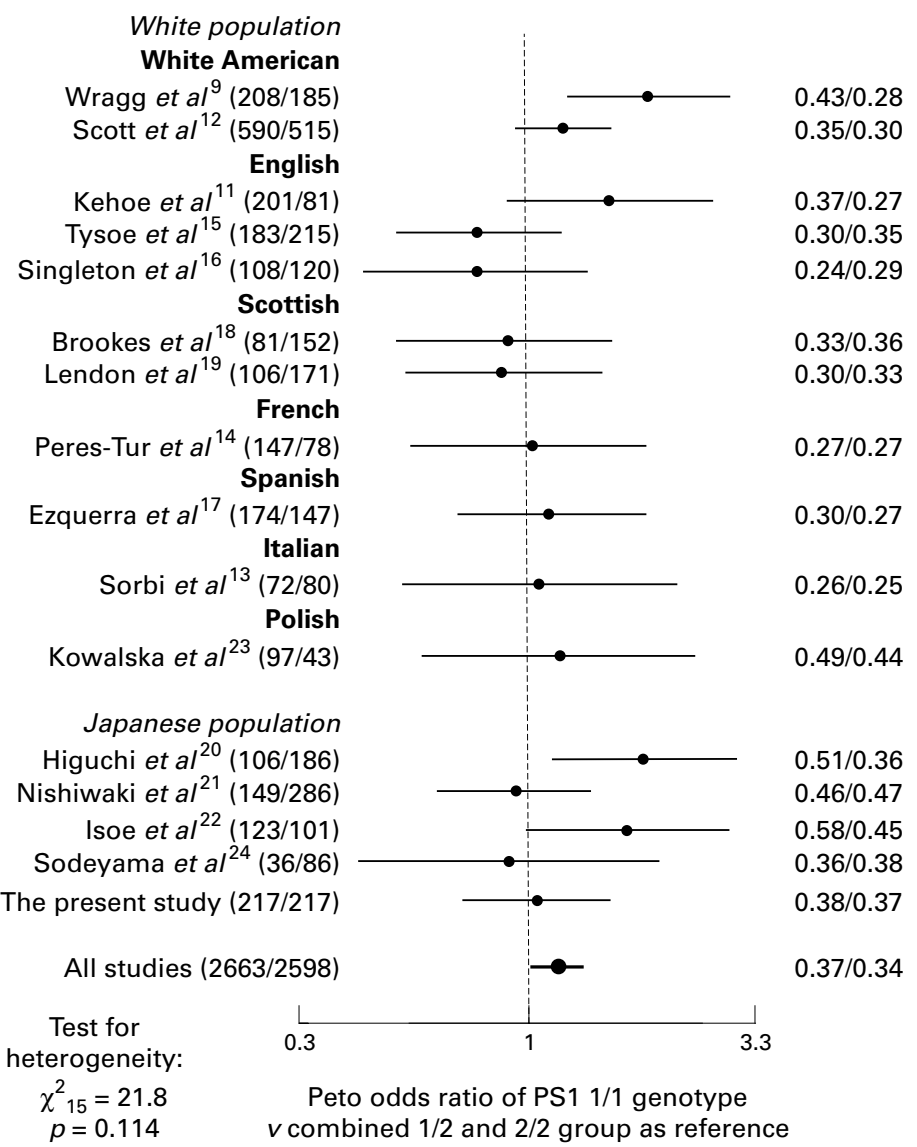

Odds ratio and $95 \%$ CIs of the presenilin-1 allele-1 in different studies ordered according to the type of population studied and within a category. AD=Alzheimer's disease; PS1=presenilin 1 . $\varepsilon 3 / 4 \quad 20 \%, \quad \varepsilon 4 / 4 \quad 1 \%) \quad(\chi 2=62.46, \quad d f=4$, $\mathrm{p}<0.001)$.

Table 1 shows the PS1 intronic genotypes and allele frequencies for Alzheimer's disease and age and sex matched control subjects. ApoE and PS1 genotypes were in HardyWeinberg equilibrium for both the Alzheimer's disease and control subjects. There was no difference in the PS1 gene polymorphism between the younger control group and the elderly control group $\left(\chi^{2}=0.12, \mathrm{df}=2, \mathrm{p}=0.943\right)$ or between early onset Alzheimer's disease and late onset patients with Alzheimer's disease $\left(\chi^{2}=0.17, \mathrm{df}=2, \mathrm{p}=0.918\right)$. There was no evidence indicating an association between the PS1 1/1 genotype and diagnosis (early onset Alzheimer's disease $v$ younger control group: $\chi^{2}=0.00, \mathrm{df}=1, \mathrm{p}=1.000$; late onset Alzheimer's disease $v$ elderly control group: $\chi^{2}=0.05, \mathrm{df}=1$, $\mathrm{p}=0.813$ ).

Table 1 also shows the PS1 genotypes and allele frequencies for Alzheimer's disease subjects and controls according to their $\varepsilon 4$ carrier status. Because of the few $\varepsilon 2$ alleles, we combined the $\varepsilon 2$ and $\varepsilon 3$ alleles and compared their distribution with that of $\varepsilon 4$ alleles in a $\chi^{2}$ analysis with the PS1 genotype as the second dimension. Among patients with Alzheimer's disease, there was no evidence that PS1 genotype frequencies were different between $\varepsilon 4$ carriers and non- $\varepsilon 4$ carriers (early onset Alzheimer's disease: $\chi^{2}=0.09, \mathrm{df}=2, \mathrm{p}=0.956$; late onset Alzheimer's disease: $\chi^{2}=0.07, \mathrm{df}=2$, $\mathrm{p}=0.967)$. In the control $\varepsilon 4$ carriers, there was a reduction in the number of subjects with the PS1 allele-2/2 genotype, but this difference was not significant (younger control group: $\chi^{2}=1.28, \mathrm{df}=2, \mathrm{p}=0.528$; elderly control group: $\chi^{2}=2.60, \mathrm{df}=2, \mathrm{p}=0.273$ ). We did not find that the patients with Alzheimer's disease who were carriers of $\varepsilon 4$ were more likely to have the $1 / 1$ genotype than were the control subjects (early onset Alzheimer's disease $v$ younger control group: $\chi^{2}=0.85, \mathrm{df}=2, p=0.653$; late onset Alzheimer's disease $v$ elderly control group: $\left.\chi^{2}=2.55, d f=2, p=0.279\right)$. Similarly, we did not find that the patients with Alzheimer's disease who were not carriers of $\varepsilon 4$ were more likely to have the $1 / 1$ genotype than were the control subjects (early onset Alzheimer's disease $v$ younger control group: $\chi 2=0.25, \quad \mathrm{df}=2$, $\mathrm{p}=0.881$; late onset Alzheimer's disease $v$ elderly control group: $\chi 2=0.05, \quad \mathrm{df}=2$, $\mathrm{p}=0.976$ ).

Table 2 gives the apoE allele frequencies among the three PS1 genotypes for the patients with Alzheimer's disease and control subjects. There was no evidence of an association between the PS1 genotype and the apoE allele frequencies among the patients with Alzheimer's disease (early onset Alzheimer's disease: $\chi^{2}=2.35, \mathrm{df}=4, \mathrm{p}=0.672$; late onset Alzheimer's disease: $\chi^{2}=0.65, \mathrm{df}=4, \mathrm{p}=0.958$ ) nor among control subjects (younger control group: $\chi^{2}=1.07, \mathrm{df}=4, \mathrm{p}=0.899$; elderly control group: $\left.\chi^{2}=5.06, \mathrm{df}=4, p=0.282\right)$. The logistic regression analysis revealed that there was no effect of the PS1 allele-1 on predicting Alzheimer's disease when the effect of apoE $\varepsilon 4$ allele was adjusted (table 3 ). 
We identified 16 studies through the literature search. The study of Mann et al ${ }^{10}$ in which data to complete a $2 \times 2$ table was lacking was not included in any of the analyses. In the study of Kehoe $e t a l^{11}$ the final analysis included some controls also reported by Wragg et al. ${ }^{9}$ We removed the control group of Wragg et al and used an amended data set in a meta-analysis. As the result, 15 studies. $^{911-24}$ and the present study that included 2598 patients and 2663 controls as a whole were included in the metaanalysis. The meta-analysis of data showed that there was a significant difference in the frequency of the PS1 1/1 genotype between patients and controls $\left(\chi^{2}=6.47, \mathrm{df}=1, \mathrm{p}=0.011\right.$; Peto odds ratio $=1.16,95 \%$ confidence interval $(95 \% \mathrm{CI})=1.04-1.31$; test of heterogeneity: $\chi^{2}=21.78, \mathrm{df}=15, \mathrm{p}=0.114$, figure).

\section{Discussion}

Wragg et $a l^{9}$ originally examined the intronic polymorphism in the PS1 gene and showed that the incidence of late onset Alzheimer's disease was twice as high in those who were homozygous for allele- 1 compared with those with either the $1 / 2$ or $2 / 2$ genotypes. This association has recently been reported for both late onset and early onset sporadic Alzheimer's disease from several laboratories. ${ }^{9-24}$ In the present case-control study, we failed to find an association between PS1 polymorphism and early onset or late onset patients with Alzheimer's disease. The regression analysis controlled for the apoE $\& 4$ allele effect also supported the idea that there is no association between PS1 polymorphism and Japanese sporadic Alzheimer's disease. However, a combined analysis showed an excess of allele-1 homozygotes in Alzheimer's disease. The most likely interpretation of the discrepancy would be a racial or ethnic difference. The PS1 allele frequencies differ markedly between the Japanese and white controls, and also between the Japanese and AfroAmerican controls, suggesting that the allele frequencies of controls vary substantially depending on the ethnic background. AfroAmerican controls have the highest frequency of allele-1 $(0.80)^{9}$ and Japanese controls have an intermediate frequency among the three ethnic groups.

Additional evidence is the variation of the PS1 allele frequencies within a white population. Although there was no difference in the frequency of the 1/1 genotype between American controls and English, French, Italian, and Spanish controls, it is interesting to note that the frequencies of the PS1 genotype of patients with Alzheimer's disease vary in different reports. Scott et al, ${ }^{12}$ Sorbi et $a l,{ }^{13}$ and Peres-Tur et $a l^{14}$ failed to detect any association between late onset Alzheimer's disease and PS1 polymorphism in American, Italian, and French populations, respectively. The studies in English populations ${ }^{15} 16$ also found no significant effect of PS1 polymorphism either in early onset or in late onset Alzheimer's diseases. The study in Spain ${ }^{17}$ did not find an excess of homozygotes for allele-1, but instead found a significant decrease of homozygotes for allele$2 / 2$ in the familial Alzheimer's disease group. In the study of Scott et $a l,{ }^{12}$ early onset sporadic Alzheimer's disease had a slightly increased frequency of allele-1, whereas two studies in Scottish populations ${ }^{18} 19$ found no significant association between PS1 polymorphism and early onset Alzheimer's disease.

The association between PS1 polymorphism and Alzheimer's disease is difficult to confirm because of the large study group size that is needed. This is because the group of subjects homozygous for allele- 2 is small, and because the effect of the apoE $\varepsilon 4$ allele, the major genetic risk factor known to influence Alzheimer's disease, is stronger than the effects of other candidate genes and is difficult to control for statistical analyses. Another limitation of the association study is that the PS1 polymorphism exists in an intron, which does not alter a splice site or the predicted amino acid sequence. Thus a direct causal effect of this polymorphism on PS1 biology is unlikely. An alternative possibility is that the PS1 polymorphism is merely a marker for another, and is in linkage disequilibrium with another locus of functional significance in Alzheimer's disease, which has not been identified.

In summary, we failed to support a relation between the PS1 gene and early onset and late onset sporadic Alzheimer's disease, nor an interaction between PS1 polymorphism and the apoE $\varepsilon 4$ allele in a Japanese population. However, a meta-analysis including both white and Japanese data sets disclosed a significant association between the PS1 1/1 genotype and Alzheimer's disease. Consequently, it may be premature to discount the PS1 gene, or less plausibly a gene in linkage disequilibrium with it, as a risk factor for Alzheimer's disease.

We thank the physicians and staff of Hyogo Institute for Aging Brain and Cognitive Disorders for performing the clinical evaluation. A part of this study was supported by grants from the Japan Pharmacopsychiatry Research Foundation (MY), the Kobe Shinryokukai Association (MY), and the Hyogo Creation and Technology Association (MY).

1 Larson EB, Kukull WA, Katzman RL. Cognitive impairment: dementia and Alzheimer's disease. Annu Rev Public Health 1992;13:431-49.

2 Corder EH, Saunders AM, Strittmatter WJ, et al. Gene dose of apolipoprotein E type 4 allele and the risk of Alzheimer's disease in late onset families. Science 1993;261:921-3.

3 Strittmatter WJ, Saunders AM, Schmechel D, et al. Apolipoprotein E: high-avidity binding to $\beta$-amyloid and increased frequency of type 4 allele in late-onset familial Alzheimer disease. Proc Natl Acad Sci U S A 1993;90:197781 .

4 Saunders AM, Strittmatter WJ, Schmechel D, et al. Association of apolipoprotein $\mathrm{E}$ allele epsilon 4 with late onset familial and sporadic Alzheimer's disease. Neurology 1993; 43:1467-72.

5 Sherrington R, Rogaev EI, Liang Y, et al. Cloning of a gene bearing missense mutations in early-onset familial bearing missense mutations in early-ons
Alzheimer's disease. Nature 1995;375:754-60.

6 Hardy J. Amyloid, the presenilins and Alzheimer's disease. TINS 1997;20:154-9.

7 Duff K, Eckman C, Zehr C, et al. Increased amyloid$\beta 42(43)$ in brains of mice expressing mutant presenilin 1. Nature 1996;383:710-13.

8 Scheuner D, Eckman C, Jensen M, et al. Secreted amyloid $\beta$-protein similar to that in the senile plaques of Alzheimer's disease is increased in vivo by the presenilin 1 and 2 and APP mutations linked to familial Alzheimer's disease. Nat Med 1996;2:864-70.

9 Wragg M, Hutton M, Talbot C, and the Alzheimer's disease collaborative group. Genetic association between intronic polymorphism in presenilin-1 gene and late-onset Alzheimer's disease. Lancet 1996;347:509-12

10 Mann DM, Pickering-Brown SM, Bayatti NN, $\beta$ protein deposited in Alzheimer's disease. Neurosci Lett 1997;222: 57-60.

11 Kehoe P, Williams J, Lovestone S, et al, and the UK Alzheimer's disease collaborative group. Presenilin-1 polymorphism and Alzheimer's disease. Lancet 1996;347:1185. 
12 Scott WK, Growdon JH, Roses AD, et al. Presenilin-1 polymorphism and Alzheimer's disease. Lancet 1996;347: polymor $1186-7$.

13 Sorbi S, Nacmias B, Tedde A, et al. Presenilin-1 gene intronic polymorphism in sporadic and familia Alzheimer's disease. Neurosci Lett 1997;222:132-4

14 Perez-Tur J, Wavrant-De Vrieze F, Lambert JC, et al, and the Alzheimer's study group. Presenilin-1 polymorphism and Alzheimer's disease. Lancet 1996;347:1560-1.

15 Tysoe C, Whittaker J, Cairns NJ, et al. Presenilin-1 intron 8 polymorphism is not associated with autopsy-confirmed late-onset Alzheimer's disease. Neurosci Lett 1997;222:68-9.

16 Singleton $\mathrm{AB}, \mathrm{Lamb} \mathrm{H}$, Leake $\mathrm{A}$, et al. No association between an intronic polymorphism in the presenilin-1 gene

17 Ezquerra M, Blesa R, Tolosa E, et al. The genotype 2/2 of the presenilin-1 polymorphism is decreased in Spanish early-onset Alzheimer's disease. Neurosci Lett 1997;227: early-onse $201-4$.

18 Brookes AJ, Howell WM, Woodburn K, et al. Presenilin-I, presenilin-II, and VLDL-R associations in early onset presenilin-II, and VLDL-R associations in early
Alzheimer's disease [letter]. Lancet 1997;350:336-7.

19 Lendon CL, Myers A, Cumming A, et al. A polymorphism in the presenilin 1 gene does not modify risk for Alzheimer's disease in a cohort with sporadic early onset. Neurosci Lett 1997;228:212-4.

20 Higuchi S, Muramatsu T, Matsushita S, et al. Presenilin-1 polymorphism and Alzheimer's disease. Lancet 1996;347: 1186.

21 Nishiwaki Y, Kamino K, Yoshiiwa A, et al. T/G polymorphism at intron 9 of presenilin 1 gene is associated with, but not responsible for sporadic late-onset Alzheimer's disease in Japanese population. Neurosci Lett 1997;227:123-26.
22 Isoe $\mathrm{K}$, Urakami $\mathrm{K}$, Ji $\mathrm{Y}$, Adachi $\mathrm{Y}$, et al Presenilin-1 polymorphism in patients with Alzheimer's disease, vascular dementia and alcohol-associated dementia in Japanese population. Acta Neurol Scand 1996;94:326-8.

23 Kowalska A, Wender M, Lannfelt L. Lack of association between an intronic polymorphism in the presenilin-1 gene and sporadic late-onset Alzheimer disease in Polish patients. Dement Geriatr Cogn Disord 1998;9:137-9.

24 Sodeyama N, Itoh Y, Suematsu N, et al. Presenilin 1 intronic polymorphism is not associated with Alzheimer type neuropathological changes or sporadic Alzheimer's disease. f Neurol Neurosurg Psychiatry 1998;64:548-51.

25 Ishii K, Kitagaki H, Kono M, et al. Decreased medial temporal oxygen metabolism in Alzheimer's disease shown by PET. F Nucl Med 1996;37:1159-65.

26 Yasuda M, Maeda K, Shimada K, et al. Apolipoprotein E $\varepsilon 4$ allele and gender difference in risk of Alzheimer's disease. Alzheimer Res 1995;1:77-81.

27 Folstein MF, Folstein SE, McHugh PR. Mini-mental state: a practical method for grading the cognitive state for the clinician. F Psychiatr Res 1975;12:189-98.

28 McKhann G, Drachman D, Folstein M, et al. Clinical diagnosis of Alzheimer's disease: report of the NINCDSADRDA Work Group under the auspices of Department of Health and Human Services Task Force on Alzheimer's disease. Neurology 1984;34:939-44.

29 Wenham PR, Price WH, Blandell G. Apolipoprotein E genotyping by one-stage PCR. Lancet 1991;337:1158-9

30 Yusuf S, Peto R, Lewis J, et al. $\beta$-Blockade during and after myocardial infarction: an overview of the randomized trials. Prog Cardiovasc Dis 1985;27:335-71. 